\title{
La lectura inicial: ventana para acceder a mundos posibles
}

\author{
Margarita Rosa de la Hoz Pertuz \\ margaritar1108@hotmail.com \\ Institucional Educativa David Sánchez Juliao
}

\section{Resumen}

Este artículo se deriva de la investigación "aprendamos todos a leer", resultado del proyecto de la Secretaría Distrital de Educación en el nivel de Educación preescolar, grado de transición con "la lectura inicial: ventana para acceder a mundos posibles. La metodología es de acción-reflexión en el aula, consistente en promover los vínculos afectivos que unen al niño con el mundo de la vida, en el ejercicio de la lectura compartida y permitiendo al infante manifestar su interpretación para que vuele su imaginación a esos sueños de infancia. Los resultados reflejaron el deleite que los niños sintieron a través de un aprendizaje experiencial de la lectura unido a un significativo valor didáctico. Estos placeres, grandes o pequeños provistos por la lectura fueron incluso para aquellos en los que su proceso fue retardado. Se concluye que los niños que adquirieron los procesos de la lectura en este nivel, aprenden a leer más rápido y con mayor facilidad. Lo más importante en el estudio es la consideración que los niños reconozcan los códigos lingüísticos de la escritura y su relación con el habla, para descubrir cada tesoro que la lectura les ofrece. Las lecturas compartidas con adultos permitieron en ellos una mejor comprensión y no solo el descubrir el código secreto de la lectura, sino que es la llave que les abre las puertas a mundos imaginarios.

\section{Palabras Clave}

Preescolar, aprendizaje experiencial, lectura, afectividad.

Recibido 12/10/2019 - 5/11/2019 


\section{A leitura inicial: janela para acessar mundos possíveis}

\section{Resumo}

Este artigo é derivado da pesquisa "Todo aprendeu a ler", resultado do projeto da Secretaria Distrital de Educação no nível pré-escolar, grau de transição com "a leitura inicial: janela para acessar mundos possíveis". A metodologia é a ação-reflexão em sala de aula, que consiste em promover os vínculos emocionais que unem a criança ao mundo da vida, no exercício da leitura compartilhada e em permitir que o bebê expresse sua interpretação para que sua imaginação voe para esses crianças sonhos. Os resultados refletiram o prazer que as crianças sentiram por um aprendizado experimental da leitura, juntamente com um valor didático significativo. Esses prazeres, grandes ou pequenos, proporcionados pela leitura eram mesmo para aqueles em quem seu processo estava atrasado. Conclui-se que as crianças que adquiriram os processos de leitura nesse nível aprendem a ler de maneira mais rápida e fácil. A coisa mais importante no estudo é a consideração de que as crianças reconhecem os códigos linguísticos da escrita e sua relação com a fala, para descobrir todos os tesouros que a leitura lhes oferece. As leituras compartilhadas com os adultos permitiram uma melhor compreensão e não apenas para descobrir o código secreto da leitura, mas é a chave que abre as portas para os mundos imaginários.

\section{Palavras chave}

Pré-escola, aprendizagem experiencial, leitura, afetividade, códigos linguísticos. 


\section{Introducción}

En el marco del programa de la secretaria distrital de educación "aprendamos todos a leer", se emprende un proyecto de investigación desde la condición de docente de Educación preescolar del grado de transición, en el que, comprometida con este proyecto, se da inicio al mismo con la pregunta: ¿Cuáles son las estrategias, los métodos y técnicas que han sido más favorables para estimular la lectura inicial en el niño? ¿Cuáles son las estrategias, métodos o técnicas que se utilizan en la Institución Educativa David Sánchez Juliao?

Entre los antecedentes se destacan: el trabajo de Valdivieso, L. B. (2013). El objetivo de este libro es mostrar que una parte importante del éxito en el aprendizaje del lenguaje escrito depende del desarrollo psicológico cognitivo y psicolingüístico en los años anteriores al ingreso al primer año básico. Nos muestra que el aprendizaje de la lectura y es unproceso que no solo depende los docentes y que el uso del contexto circundante es muy importante. Por otra parte, Bravo Valdivieso, L., Villalón, M., \& Orellana, E. (2004) realizaron estudios sobre las fases del aprendizaje lector que muestran que aprender a leer se produce siguiendo una secuencia de estrategias cognitivas para la correlación entre el lenguaje oral y la literacidad inicial, como funciona la mente del niño a partir de su participación en las actividades propuestas, su ritmo de aprendizaje y nivel de maduración de las etapas del proceso, el reconocimiento de las palabras, a partir de la lectura inicial y psicología cognitiva.

Los mismos autores Bravo Valdivieso, L., Villalón, M., \& Orellana, E. (2006) en un trabajo posterior estudian el procesamiento perceptivo visual-ortográfico en el aprendizaje del lenguaje escrito; se diferencia de una percepción visual de conocer las letras, no es solamente un proceso perceptivo visual de las diferencias gráficas, sino que implica una internalización de las variaciones fonética en la lectura inicial estudiado desde la psicología cognitiva en relación con la predictibilidad del lenguaje a partir de los ejercicios de prelectura, el cual relacionamos con el trabajo de Trillos (2011) y el prólogo del libro en el que Ballesteros (2011) dice en relación a la construcción,

de un sistema de pensamiento a partir del lenguaje que devela, además, su estar- en- elmundo afirmado por Heidegger. Forma de un conjunto de significantes que no solo designan o señalan los elementos y su entorno, sino que se constituye en un complejo 
andamiaje a partir y no a través del cual se emprende una larga marcha que conduce ineludiblemente al encuentro del ser humano. No confundir con la búsqueda del "mí mismo", tan en boga en tiempos de exaltación del individualismo, que presupondría el eslogan cinematográfico que rezaría: mátelos a todos y regrese solo. A propósito de dicha desviación Hannah Arent diría: “...que yo sepa nadie se ha encontrado a sí mismo". Buscar al ser humano, como lo afirma Trillos, solo es posible en el marco de sus relaciones sociales; ningún estudio del lenguaje para llegar a él podría hacerse por fuera de su entorno, contrario a lo que los teóricos del "ágora” contemporánea o "la galaxia internet", quienes apuestan al hombre por fuera de su estructura social y lo ubican en el estrecho círculo de lo que denominan red. La labor esencial que la lingüísticaplantea Jakobson- en todos sus planos, tiene que desarrollar en la época actual consiste en el esclarecimiento de la relación entre el significado general de un signo verbal y su contexto, ya que la "dependencia contextual" La facultad predictiva del Lenguaje es la propiedad decisiva de nuestra lengua, y es previa a la creatividad.

Otro antecedente es el de Mendoza, Q., \& Verónica, B. (2015). Que trata de las habilidades meta cognitivas de la docente de párvulos y su influencia en la creatividad en los niños de 5 a 6 años en cuanto al uso de estrategias de meta cognición. En este trabajo se analizan los diferentes problemas para desarrollar la creatividad en los niños y niñas. Ante la necesidad de los docentes de preescolar deben potenciar un sinnúmero de conocimientos, estrategias y habilidades, siendo que la educación se enfrenta al gran reto de trasmitir a los niños una nueva información. Un estilo preferido de aprendizaje en un niño puede favorecer a tener éxito en el aula de clases, siempre y cuando las educadoras (res) puedan responder a las necesidades de los diferentes estilos de aprendizajes que requiera cada niño. Así mismo, de acuerdo a lo investigado, también interesó como estimular la creatividad, esto significa promover a niños que sepan analizar, pensar y resolver problemas a los que se enfrenten a la búsqueda de mejores formas de vida. El rol que juega la docente dentro del desarrollo integral del niño desde sus inicios en la etapa escolar, de ella depende que la creatividad que puede tener los niños sea explotada de la mejor manera convirtiéndose así en el ser que guiara esta primera etapa de su vida. La metodología se ocupa de la parte operatoria del proceso, del conocimiento a ella responde: a métodos, técnicas, estrategias, actividades como herramientas que intervienen en esta investigación.

Pero además el desarrollo de los talleres propuestos por la Secretaria Distrital despertó la preocupación de poder desarrollar al máximo el potencial del niño para el aprendizaje de la lectura en la lengua española. Dentro de este proyecto se consideró que el entorno familiar 
provee al niño de experiencias que facilitan el desarrollo máximo del potencial que cada niño posee y le motivan a comprender el incomprensible mundo de los adultos llenos de signos y símbolos que el aún no alcanza a comprender.

Es casi imposible considerar que en una ciudad tan desarrollada como Barranquilla y su área metropolitana, que conforman el Distrito especial, los niños entre cinco y seis años no tengan conocimiento de la naturaleza de ese "objeto cultural", que heredamos en el periodo de la Colonia con los conquistadores venidos de España. En el ámbito del suroccidente de Barranquilla no existe una cultura lectora, pero se puede hacer uso de otros elementos como las etiquetas de los alimentos y diferentes productos comerciales, los carteles, avisos publicitarios, libros de cuentos aportados por sus padres, la televisión, el internet, etc. Esos niños que plantean preguntas realmente difíciles muchas veces de responder y que a partir de la observación de su contexto se interrogan acerca de esos fenómenos observados, les causa admiración o curiosidad para el aprendizaje, como lo expresan Vieytes y López:

el niño curioso, activo y creador por naturaleza, se enfrenta desde temprano con la escritura, con este tipo particular de grafías diferentes al dibujo, que están presentes en el medio, dentro y fuera de sus hogares. En los medios urbanos, esto sucede con la señalización de las calles, carteles de propaganda, anuncios, etiquetas y todo tipo de mensajes escritos... El niño se enfrenta pues precozmente, con un objeto que irá tratando de comprender: el sistema de escritura (Vieytes; López. 1992, p.40).

Se analiza el nivel de desarrollo de la lecto-escritura en este grado de preescolar, como los niños van adquiriendo la habilidad de leer a partir de reconocer las grafías que corresponden a los sonidos que representan las cosas llevándolos desde su oralidad a esa literalidad inicial. Establecer las razones por las cuales se debe aprender a leer en el prescolar y no en la primaria. Las implicaciones que tiene aprender a leer a esta temprana edad y por último la metodología, los resultados y las discusiones que se suscitan a partir de estos. Cabe resaltar que el distrito de Barranquilla supera la media nacional que es de un $50 \%$ de literalidad de los niños al final de este grado y se ha sobrepasado el porcentaje de $68 \%$ en algunos años lectivos y como consecuencia de ello la calidad educativa se ha mejorado en los últimos 12 años, de ahí que este plan lector desarrollado en el preescolar y en los niveles 
subsiguientes muy bien han podido ser la clave para lograr altísimos niveles de desarrollo en la calidad educativa de las instituciones educativas.

\section{El desarrollo de la lecto-escritura en el nivel preescolar.}

Está demostrado científicamente que los niños adquieren conocimiento desde el nacimiento (Penfield; Perot, 1963). En la medida en que crecen la habilidad comunicativa se va tornando en más compleja. Para que este proceso llegue a su fin, en primer lugar, los docentes debemos prever nuestras prácticas, modificar los criterios de selección de los textos valiosos de autores reconocidos. Algo bien importante en este punto, es el que se relaciona básicamente con la selección de textos adecuados e interesantes. El leer se relaciona directamente con la conexión que une al docente y al niño con la lectura. El interés por la lectura y la motivación por ella radica en este aspecto. Las prácticas lectoras dependen del buen ejemplo del docente; sí éste no lee, o lee muy poco, escasamente puede aconsejar, recomendar o estimular a sus estudiantes para que lo hagan en los niveles más avanzados al preescolar.

Este problema de la docencia tiene una estrecha relación con la formación profesional adquirida. Existe la necesidad de revisar las prácticas y la relación directa que se da entre el docente y la lectura, implica ser formadores de nuevos lectores o futuros escritores a partir del ejemplo. El propósito es tener las aulas llenas de docentes apasionados por la lectura para poder observar luego como se produce la función multiplicadora que se provocará en sus estudiantes. El simple hecho de llevar los libros de referencia al salón despierta el interés del niño por saber que está leyendo su profesora. Enseñar a "leer" no solo con los ojos o el entendimiento sino con el corazón y la imaginación, invitará a atravesar fronteras, a incursionar en nuevos mundos, a hacer posible lo imposible. Es nada más ni nada menos, que formar libres pensadores, lectores críticos que puedan expresarse y defender sus ideas sin temor.

Por lo general en las aulas de nivel inicial se piden cada año "un librito" para la biblioteca del salón de clases. En este caso, el poder de selección de los contenidos de los mismos escapa de las manos del docente y pasa directamente a las familias que son las encargadas de comprarlo y elegirlos. Importante sería, que sean los docentes los que eligieran 
qué libros comprar y cuáles no. La docente puede proponerles a los padres una lista de títulos de textos. (Bustillos, J. K. L., \& Reyes, V. 2018).. En este nivel es importante la responsabilidad del docente en la selección de la cultura que se le provee al niño para adquirir. Cada año al adquirir los materiales para usar durante el ciclo lectivo, por ejemplo, cuántas veces nos hallamos frente a "libritos" didácticamente inapropiados, cuyas historias están escritas sin mayor contenido y la mayoría de las veces con finales dudosos o carentes de un mensaje o moraleja, con una pobreza literaria extrema, que beneficia poco o nada a quienes escuchan esas historias. La presencia de una multiplicidad de textos: libros, cuentos, revistas, listas de compras, pendientes por hacer, lista de los compañeros de clase, etiquetas de productos comerciales, juegos didácticos, rondas, etc., permiten al niño que haga el nexo entre lo hablado y lo escrito. La biblioteca en el aula es de trascendental importancia y debe tener libros capaces de incentivar, de dar placer de acercar a los niños para que se apropien de ella. (Venegas, P. F. M., \& Roa, J. D. D. V. 2019).

La tarea alfabetizadora sienta las raíces profundas y complejas no solo de la lectura sino del aprendizaje posterior, no se alfabetiza solo al enseñar a conocer las palabras, las letras o los textos. Hay que conectar la lectura al mundo de vida al contexto local y a los demás aprendizajes. Al respecto señala Soto Molina enfatiza que,

La palabra es mediadora entre el individuo y las cosas; como también del mismo modo el lenguaje esta interpuesto entre las comunidades lingüísticas y el contexto social circundante. El lenguaje surge del pueblo y se vierte en el mismo, determinándolo y posibilitando el desarrollo de sus fuerzas espirituales. No solo se crea, sino que es transformador de la materia heredada, lo cual viene a ser la forma de la lengua y a la vez es su tradición, tanto de las formas de decir como de las maneras de pensar (2017:140).

El poder del lenguaje radica en su capacidad transversal de atravesarlo todo. Mediante el uso del lenguaje escrito, se ponen en juego diversos propósitos, se tienen en cuenta también las situaciones comunicativas, sobre todo aquellas que se desarrollan con una frecuencia tal, que garanticen en los niños la continuidad mediante la cual, dichos acercamientos con las prácticas del lenguaje prosperen hasta lograr que se apropien totalmente de las mismas. El lenguaje le permite al niño expresar pensamientos, ideas, sentimientos y a aclarar interrogantes que en ese estadio de la vida no son comprendidos. Para Bavister, S., \& Vickers, A. (2011), de igual manera el lenguaje le permite al niño comunicarse con los demás, 
establecer y comprender acuerdos sociales, relacionarse con el otro y acceder a su mundo o cosmovisión. Hay que estimular el uso del lenguaje en casa, en la escuela y en la comunidad. En el Nivel inicial, es de fundamental importancia, el iniciar a los niños en estos aprendizajes y retomar la enseñanza en aquellos que ya avanzaron en el uso de las prácticas sociales de lectura y escritura.

\section{De la oralidad a la literacidad inicial}

En el nivel inicial el objetivo primordial es la estimulación del lenguaje oral, realizando para ello diversas actividades como juego con palabras, a partir de lo cual los niños notan las múltiples posibilidades que el lenguaje diario les ofrece. Se comienza por facilitar al niño el contacto con diversos elementos de uso cotidianos, es así como se comienza a acercar al niño a la lectura. Acercar los textos a los pequeños es la manera como aprenden a leer leyendo, esto les posibilita previamente realizar anticipaciones del contenido del texto de la mano de las imágenes (el contenido gráfico) en este momento es muy importante.

Se sabe, que se hace lector leyendo, pero también escuchando a otros lectores, la variedad de autores en cuanto a propuestas literarias ampliará el universo lector de cada uno de los niños. Es importante que al inicio del proceso la docente de preescolar les lea en voz alta diversos textos a los niños. El sonido de las distintas combinaciones de letras del alfabeto, otorga los patrones rítmicos de la lengua adquirida, entre otros posibilitan las rutas del recorrido del aprendizaje de la lectura y la escritura asegura (Stanovich, et al, 1986).

El valor que tienen estas prácticas lectoras reside, en que posibilitan diferentes alternativas y el uso de diferentes estrategias lectoras. El aprehender a "escuchar", a aportar anticipaciones, permite alcanzar el placer, al pedir una y otra vez que se les narre la misma historia, en cada nueva narración descubren el humor, la tristeza y la magia, un elemento nuevo, etc. El entorno en el cual se desenvuelven los niños, que es el aula es un dispositivo permanente, si está preparado para eso. Colocar letreros, carteles, poesías en láminas en las paredes, siempre accesibles a los niños, escritas en imprenta mayúscula provocará el interés por saber que dicen o intentar descubrirlo, leyendo ellos mismos. Leer en compañía de un adulto es el momento ideal para que el pequeño comprenda lo que es la escritura. Leerles en 
voz alta, señalar las letras, y que esas letras conforman las palabras, y ver las ilustraciones que esas palabras representan, a la vez le ayudará a comprender el sentido de la escritura en su generalidad. Y que cada palabra tiene un significado en sí misma. Iniciarlos en la lectura y en sus convenciones, lo ayuda a aprender cómo abordar un texto. Al leerle en voz alta, es importante realizar una pausa de vez en cuando, y señalarle las distintas letras y palabras que el relato contiene; como así también relacionarlas con los dibujos que representan cada una de ellas.

El poder disfrutar a diario de experiencias lectoras con los niños, acompañar con ellos el placer del tiempo compartido, el gozo de la escucha, favorecerá el desarrollo de la fantasía y sentará las bases de futuros lectores, que aprovechan el tiempo leyendo, escuchando y compartiendo. En ese maravilloso momento cotidiano en el que todo se detiene y solo se deja correr la imaginación, docentes y padres son portadores de la llave secreta del éxito, que conduce a ese mágico mundo, no dudemos en abrirles las puertas lo antes posible.

Los niños que se han puesto en contacto con la lectura a muy corta edad, aprenden a leer más rápido y con mayor facilidad. La investigación muestra que a mayor experiencia y manejo del lenguaje en el preescolar se maximizan las posibilidades de éxito del estudiante en la adquisición de las habilidades requeridas para el dominio no solo de la lectura y la escritura sino para comprender el mundo. Lo realmente valioso no es que reconozcan los códigos de la letra escrita, sino que nazca en ellos el deseo de descubrir todos los tesoros que la lectura les promete. Y cuanto más disímiles sean las lecturas compartidas, mejor comprenderán que más que un descubrir el código secreto, la lectura es la llave que abre la puerta a mundos fantásticos (Sulzby, et al,1989). Poco a poco su lenguaje interior se irá conformando, así se sentirá seguro y podrá disfrutar, plenamente, del discurso literario. Hay muchas ocasiones que son propicias para compartir una buena lectura: al viajar en el carro, mientras retomamos el camino a casa, escuchando una grabación con uno o varios cuentos... Pero, verdaderamente, el momento especial para llevar a cabo esa lectura compartida es, obviamente, en su cuarto, cuando el niño se va a dormir. Por ello se debe comprometer a los padres en este proceso.

Al efectuar la lectura, el adulto no solo recrea la historia con su voz, sino que debe además incorporar sus dotes actorales para sacar a luz la emoción y el suspenso que el relato 
conlleve. Si al finalizar la narración, el niño quiere hacer algún comentario, acerca de lo que el cuento le dejó, hay que detenerse a escuchar su reflexión sobre lo que acaba de oír. Pero el comentario debe ser siempre espontáneo, no se lo puede forzar a que realice un relato. Y siempre, de más está decirlo... leer el cuento del principio al fin. Los niños a los que se les lee desarrollan un mayor gusto y aprecio por la lectura, adquieren léxico y comprenden que la escritura es la representación del lenguaje oral

El cuento de la noche debe tener un ritual propio. Para comenzar, será preciso que se le asigne un tiempo exclusivo, dedicado sólo a disfrutar juntos de la lectura, sin padecer interrupciones. Tanto el adulto como el niño, tienen que sentirse cómodos, a gusto: sentados o acostados, siempre cerca uno del otro para que el pequeño logre contemplar las imágenes sin dificultad y también para intercambiar instantes de afecto. La elección puede realizarla el niño, aunque también es bueno que se le ofrezca alguna otra propuesta.

\section{Por qué se debe aprender a leer en el preescolar y no en la primaria.}

La literatura consultada indica que el $50 \%$ de los niños en edad preescolar aprende a leer y a escribir sin dificultad ciertas palabras. Pero ¿qué pasa con el porcentaje restante? El porcentaje restante por no tener un ambiente apropiado en el cual hayan podido adquirir un buen nivel de lenguaje oral y una coordinación de movimientos adecuada tendrán dificultades en la parte cognitiva debido al retraso en el desarrollo del lenguaje. Las mediciones indican que el $34 \%$ de ese $50 \%$ no alcanzan los niveles de lectura esperados para su edad incluso al llegar al $3^{\circ}$ grado del nivel primario. Bajo el enfoque (cognitivo) la lengua constituye una de las funciones esenciales, a través de la cual la vida del sentimiento y de la voluntad se organiza y alcanza de forma específicamente humana, según Soto Molina (2016). De acuerdo con la nueva psicología cognitiva, el lenguaje no es un producto de maduración del sistema nervioso, sino que es el productor de nuevas formas de vida cognitiva a partir de la edad de los 6 años. La no lectura a esta edad desencadena fracaso escolar, deserción del sistema y limitado acceso y éxito en el mundo del trabajo en edad adulta según Barnett y Ackerman, (2005).

Didácticamente es interesante conocer cómo va madurando el niño en el aspecto lingüístico y correlacionar esta maduración con la de la inteligencia. Desde el punto de vista 
del lenguaje, primero emitimos sonidos, luego silabeos y palabras. Poco a poco el niño empieza a expresar ideas mediante frases sencillas hasta que consigue expresarse de forma clara a través del lenguaje. Una vez que domina los mecanismos básicos del lenguaje oral, se inicia el gran reto: aprender a leer y escribir. Pero, ¿en qué consiste realmente el lenguaje escrito? El lenguaje escrito es una característica exclusivamente humana que requiere un desarrollo intelectual elevado propio de sociedades desarrolladas. En este proceso intervienen muchos factores sobre el que recaen diferentes influencias, como el hecho de poder comunicar mensajes, pensamientos e ideas a través de símbolos. De tal forma que dichos mensajes perduren en el tiempo sin necesidad de que emisor y receptor coincidan en el tiempo. La adquisición del lenguaje supone un complejo proceso de aprendizaje, donde se mezcla la imitación y la creación personal. A medida que el niño descubre las cosas y las relaciona con las palabras, siente la necesidad de comunicarse y esa necesidad le obliga a inventar, pero llega un momento que aparece el valor social del lenguaje. Aprendemos lenguaje a través del lenguaje y sobre el lenguaje (Halliday, 1980).

Por ello comprometer a los padres de los preescolares en esta actividad de adquirir la habilidad de lectoescritura en los niños es esencial. Por esto, es estimado que la edad ideal para el aprendizaje de la lectoescritura es en torno a los 6 años. Antes de esta edad, se pueden hacer actividades que faciliten el posterior aprendizaje. Frecuentemente se producirán escrituras colectivas, niños que dictan textos a otros niños que los escriben como pueden o en su defecto se los dictan a la docente. El acceso a los primeros esbozos de escritura, van unidas a la lectura indefectiblemente. Mientras comienza a acceder a una, en paralelo va accediendo a la otra. Al comenzar a escribir las primeras letras, le ayudará a comprender y a aprender que cada una de ellas tiene un signo gráfico y un sonido particular. El conocer las letras le posibilitará poder comenzar a deletrear las palabras. Esto será un esfuerzo enorme para ellos y será digno de ser felicitado y estimulado por ello, aunque al escribir no tenga en cuenta las reglas ortográficas.

La lectura y la escritura van juntas. Mientras que el niño aprende una, simultáneamente está aprendiendo la otra. Los garabatos y los dibujos son sus primeros esbozos de escritura. Pronto empezará a escribir las letras del alfabeto. Esto le ayudará a discriminar los diferentes sonidos que cada una de ellas representa. Al ir descubriendo las 
letras y los diversos sonidos, éstos le darán la noción sobre cómo deletrear las palabras. Cuando comience a escribir palabras enteras, muy posiblemente lo realizará cometiendo errores ortográficos. De todos modos, será digno de valorar su esfuerzo, y nos daremos cuenta de que su intento es bastante bueno por ser la primera vez.

Para cuando alcanzan la edad de 4 años, los niños empiezan a entender que las palabras escritas contienen un significado. A los 5 años, la mayoría comienza a notar que las palabras están ubicadas espacialmente de izquierda a derecha. Muchos niños, en esta etapa, inclusive comienzan a identificar letras mayúsculas y minúsculas y a "leer" palabras simples. Al finalizar el nivel inicial, el niño tal vez quiera leer por su propia cuenta. Será importante permitir que lo haga, pero siempre y cuando esta iniciativa surja de él mismo. La lectura debe ser un motivo por el cual se sienta orgulloso.

Penfield (1963) afirma que después del llanto de neonato el niño emite desde muy pronto sonidos que no tienen significación lingüística, pero que son muy importantes en la adquisición del lenguaje hablado. Este periodo comienza alrededor de los dos o tres meses y durara hasta el final del primer año; es la fase "prelálica" o pre verbal, en la que participan el llanto, los gritos, gemidos y, especialmente, los balbuceos y "gogeos", que refuerzan las cuerdas vocales; aunque es preciso señalar que el balbuceo no constituye propiamente el lenguaje hasta que sea empleado en forma interjeccional.

A los nueve meses el niño es capaz de mantener monólogos incomprensibles, no continuados, sino esporádicos. A partir de los doce meses las palabras comienzan a tener significado; es el momento de la palabra-fase; el niño usa las mismas palabras que antes pero ya no están vacías de significado, y se observan acompañadas de gestos y mímica en general; tales palabras suelen tener carácter imperativo, desiderativo o interrogativo. El niño incorpora la entonación para significar.

A partir de los dos años las palabras ya sirven para nombrar las cosas, lo cual no significa que sean forzosamente correctas, puesto que surgen imperfecciones surgidas de la dificultad de la misma palabra. Esta etapa coincide con la "primera edad de las preguntas" (18-20 meses). En el mismo nivel y hacia los tres años se sitúa la "segunda edad preguntadora", en la que el niño más que el nombre de los objetos le interesa su razón de ser. 
Es la edad del ¿por qué? Ese "por qué” tiene una función intelectual de información y otra afectiva (entrar en contacto con el adulto), que también podría entenderse como social. Piaget, según Wadsworth, B. J. (1996), ha subrayado que ese "por qué" no tiene una orientación causal, sino finalista; lo que el niño busca y procura mediante sus preguntas, no es una explicación objetiva, sino la relación que puede existir entre el objeto de su pregunta y sus necesidades, deseos o temores. El lenguaje de este modo contribuye a la objetivación del universo y del individuo. El niño va almacenando su acervo cultural, el cual va aumentando lo que ya está almacenado. La cultura humana es una realidad dinámica en el infante.

De los cuatro a seis años el repertorio lingüístico se acrecienta y el pensamiento se empieza a configurar. Un punto importante a tener en cuenta en este sendero, es el que se relaciona básicamente con la selección de textos adecuados e interesantes, el que leer se relaciona directamente con la conexión que une al docente con la lectura. He aquí el problema mayor a resolver. Se deben prever nuestras prácticas lectoras. Si el docente no lee, o lee muy poco, poco podrá aconsejar, recomendar o estimular a sus discípulos para que lo hagan. Este problema de la docencia tiene una estrecha relación con la formación profesional adquirida. Volver sobre este problema revisar las prácticas y la relación directa que se da entre el docente y la lectura, bastará para poder retomar el camino duro y desafiante que propone el ser formadores de nuevos lectores o futuros escritores. El propósito es tener las aulas llenas de docentes apasionados por la lectura para poder observar luego como se produce la función multiplicadora que se provocará en sus alumnos. Enseñar a "leer" no solo con los ojos o el entendimiento sino con el corazón y la imaginación, invitará a atravesar fronteras a incursionar en nuevos mundos, a hacer posible lo imposible. Es nada más ni nada menos, que formar libres pensadores, lectores críticos que puedan expresarse y defender sus ideas sin temor.

Es necesario que los niños participen en la elección de los textos, a la hora de optar por un cuento para leer, tan necesario como el que puedan acceder a visitar otras bibliotecas. El punto aquí es formar una comunidad de pequeños y pequeñas lectoras. Para ello es preciso respetar al niño lector, en toda la dimensión que eso implica. Brindando los docentes un 
trabajo serio previo, en cuanto a la selección de los contenidos, a enseñar, elección de los autores, y básicamente tomarse el tiempo de leer "todo" el material antes que lo haga el niño. Animarse a incluir dentro de la bibliografía seleccionada, textos extensos o con un vocabulario complejo. Con el correr del tiempo se podrá apreciar, que la atención de los pequeños cada vez será mayor, y no representará obstáculo alguno, sobre todo sí lo que está escuchando le resultará atractivo e interesante.

\section{Lo que implica "aprender a leer"}

La afirmación que aprender a leer implica comprensión y apropiación del código alfabético del español, de la conciencia del sonido, hasta el dominio de la grafía, ha estado vigente por años. Sin embargo, el alfabeto ha colmado la atención de los pedagogos del lenguaje y de la educación infantil. Las letras por si solas carecen de sentido. Son simples símbolos convencionales que no representan al pensamiento ni las ideas. Pero si se les relaciona con el sonido que representan cobran sentido. Los niños deben aprender que detrás de cada sonido o fonema (22) es que existen las letras (27), además de 5 dígrafos. Los niños deben comprender esto desde una habilidad oral previamente desarrollada y que les permite discriminar y diferenciar los sonidos

Se conoce como conciencia fonológica al reconocimiento de cada sonido y su relación con las letras o grupos de ellas (sílabas) que forman las palabras. Esta comprensión es indispensable, ya que solo se logra a través de la instrucción directa, debido a que no es una capacidad innata, ni se desarrolla de manera natural. La conciencia fonológica la adquiere el niño en el aula y los niños que más la dominan pueden ejecutarla fuera del salón de clase, en sus hogares (Tabors; Dickinson, 2001).

Mientras que la decodificación es entendida como la capacidad de deslindar cada uno de los sonidos que conforman una palabra, es decir la capacidad de discriminar el código que subyace a la construcción de la palabra. Esta acción de aparente sencillez requiere ser enseñada explícitamente por una docente experta y requiere de una metodología especial. Ciertas actividades como rimas, jerigonzas trabalenguas y poesías actuadas permiten el dominio de esta habilidad para desarrollar patrones fónicos que abren a su vez, la senda del reconocimiento de los sonidos. 


\section{Metodología}

El primer periodo fue la reflexión y observación directa de las clases de español en el área del lenguaje en el grado transición, niños y niñas de entre 5-6 años. Luego, entrevistas entre los docentes observados, los tutores del proyecto y supervisores de educación. De igual manera, análisis comparativo de los datos obtenidos en los puntos precedentes e identificación de los elementos discordantes y concordantes de las estrategias, métodos y técnicas aplicadas por los docentes y las establecidas en las guías Aprendamos a leer Preescolar.

La contrastación de los datos obtenidos por los diferentes métodos permitirá detectar y corregir la disparidad de cada uno y mejorar el valor de la información recogida. La triangulación de la información permitió aminorar las limitaciones que comprende su análisis por separado. La secuencia que se consideró más conveniente fue la siguiente:

- Observación directa de la actividad de clase, llevando dos tipos diferentes de registro: Un registro con notas de campo en forma directa.

Una ficha con apartes post- registro. Las mismas se completan finalizada la actividad.

- Entrevista en profundidad a los docentes de español de los tres salones de nivel transición 5-6 años de nuestra Institución Educativa.

La recolección de datos fue realizada durante el período Julio-octubre de 2019. Se les hizo seguimiento a 25 de los estudiantes de la población total de 75 niños. Se observaron y entrevistaron todas las docentes del área español de los grados de transición (5-6 años); en total tres docentes, dos la sede principal y una de la sede alterna.

Las observaciones se realizaron en el período comprendido entre los meses de agosto y septiembre; su número osciló entre seis y nueve, de acuerdo al nivel de desarrollo de los niños en su proceso de adquisición de la lectura. Las notas de campo fueron transcritas y se desarrollaron conceptos y proposiciones para dar sentido a los datos; estos se compararon, y se establecieron las relaciones o divergencias de las docentes según el nivel en que desarrollan su actividad. 
Con respecto a las entrevistas hay que puntualizar que se utilizaron recursos tecnológicos de audio; este procedimiento en ningún momento representó un agente intimidatorio para el entrevistador o el entrevistado. Pues lo realizó la tutora con suma discreción. Cada sesión duró entre veinte y treinta minutos. Las entrevistas fueron transcritas y a través de la lectura profunda de las mismas se establecieron las categorías, como un modo de codificar los datos cualitativos.

Se elaboró a partir de entonces un resumen con las ideas fundamentales de cada entrevista y se trató de interpretar qué aspectos describía y resaltaba cada docente y se establecieron los elementos comunes entre ellas.

Una vez estudiados y analizados estos datos por separado, se procedió a la contrastación de los mismos en forma simultánea, estableciendo si las categorías emergentes de las entrevistas coincidían con los conceptos y proposiciones establecidas en las observaciones realizadas para cada maestra.

Finalizada la etapa de investigación, de recolección de información y análisis de los datos, se pudo establecer que las docentes integrantes sujetas de la investigación son todas egresadas licenciadas en Educación Prescolar y quien desarrolló este proyecto es además licenciadaen educación primaria con énfasis en español y literatura.

Esto determinó que la mayoría de las maestras estuvieran en conocimiento de las nuevas tendencias acerca de la enseñanza de la Lectura.

A continuación, se detalla los aspectos coincidentes del análisis:

\section{Con respecto a las docentes:}

- Se pudo establecer a través de las observaciones y de las entrevistas la idea de las docentes con respecto al proceso de adquisición de la Lectura y la Escritura. Todas ellas distinguen estos procesos como dos aspectos diferentes del quehacer educativo que no necesariamente deben ir juntos, y que no trabajan siempre juntos. Pero que el segundo es posterior al primero y no se requiere trabajarlo en este grado

- Establecen la necesidad de incorporar la idea de los aprendizajes significativos como medio para motivar el interés de los educandos. Para lograr esto tienen en cuenta los aportes curriculares y los extracurriculares. 
- Consideran que aprender a leer es importante. No se debe obligar al niño a aprender; se lo debe motivar e incentivar con diferentes recursos, técnicas variadas y respetar sus ritmos de aprendizaje.

De las observaciones se desprende que las docentes presentaban en las actividades propuestas recursos variados, respetando las diferencias y los intereses individuales de los niños en el quehacer del aula.

\begin{tabular}{|c|c|c|}
\hline \multicolumn{3}{|c|}{ Plan de Lectura en la Institución Educativa } \\
\hline \multirow[t]{2}{*}{\begin{tabular}{l}
\multicolumn{1}{c}{ MOMENTOS } \\
ANTES DE LEER \\
Incitar a la lectura \\
Dar a conocer el propósito \\
Formular predicciones \\
Activar los conocimientos previos relativos al \\
tema \\
conocer el vocabulario
\end{tabular}} & $\begin{array}{l}\text { Estrategias } \\
\text { MUESTREO } \\
\text { Consiste en la selección que hace el lector } \\
\text { donde toma del texto tipografía, palabras, } \\
\text { imágenes o ideas que funcionan como } \\
\text { índices para predecir el contenido (algunos } \\
\text { autores la llaman lectura rápida) }\end{array}$ & $\begin{array}{c}\text { Modalidades } \\
\text { AUDICIÓN DE } \\
\text { LECTURA } \\
\text { (uno lee los demás escuchan) }\end{array}$ \\
\hline & $\begin{array}{l}\text { PREDICCIÓN } \\
\text { Predecir el tema que trata un texto, incluso } \\
\text { un bloque o apartado de un libro, el final } \\
\text { de una historia, lógica de una explicación, } \\
\text { continuación de una carta, etc. Se requiere } \\
\text { previamente del muestreo }\end{array}$ & $\begin{array}{c}\text { LECTURA EN VOZ } \\
\text { ALTA } \\
\text { (lectura en atril y lectura de impacto o } \\
\text { enfática) }\end{array}$ \\
\hline \multirow[t]{2}{*}{$\begin{array}{l}\text { DURANTE LA LECTU } \\
\text { Hacer anticipaciones } \\
\text { Relacionar imagen - texto } \\
\text { Elaborar inferencias } \\
\text { Llevar a cabo la confirmación y } \\
\text { autocorrección }\end{array}$} & \begin{tabular}{l}
\multicolumn{1}{c}{ ANTICIPACIÓN } \\
Consiste en la posibilidad de descubrir a \\
partir de una palabra o de algunas letras \\
que aparecerán a continuación, pueden \\
ser léxico-semánticas (un verbo, un \\
sustantivo, un adjetivo, etc.)
\end{tabular} & $\begin{array}{c}\text { LECTURA } \\
\text { COMPARTIDA } \\
\text { (con dramatización y canciones) }\end{array}$ \\
\hline & $\begin{array}{l}\text { CONFIRMACIÓN Y } \\
\text { AUTOCORRECCIÓN } \\
\text { Al comenzar a leer un texto, el lector se } \\
\text { pregunta lo que puede encontrar en él. A } \\
\text { medida que avanza en la lectura va } \\
\text { confirmando, modificando o rechazando } \\
\text { las hipótesis que se formuló, también } \\
\text { confirma sí la predicción o anticipación } \\
\text { coincide con la que aparece en el texto. }\end{array}$ & $\begin{array}{c}\text { LECTURA GUIADA } \\
\text { (plantear preguntas) }\end{array}$ \\
\hline \multirow[t]{2}{*}{$\begin{array}{l}\text { DESPUÉS DE LEER } \\
\text { Comprensión global y especifica de } \\
\text { fragmentos o tema del texto } \\
\text { Inferencias } \\
\text { Recapitulación } \\
\text { Reconstrucción de contenidos } \\
\text { Formulación de opiniones } \\
\text { Expresión de experiencias y emociones } \\
\text { personales } \\
\text { Aplicación de las ideas a la vida cotidiana } \\
\text { (generalizaciones) } \\
\text { Construcción de textos }\end{array}$} & $\begin{array}{l}\text { INFERENCIA } \\
\text { Permite completar información ausente o } \\
\text { implícita a partir de lo dicho en el texto, a } \\
\text { deducir información, unir o relacionar } \\
\text { ideas expresadas en los párrafos, así como } \\
\text { dar sentido a palabras o frases dentro de un } \\
\text { contexto. }\end{array}$ & $\begin{array}{c}\text { LECTURA POR } \\
\text { PAREJAS } \\
\text { (Niños adelantados con los que } \\
\text { presentan dificultades) }\end{array}$ \\
\hline & $\begin{array}{l}\text { MONITOREO O METACOGNICIÓN } \\
\text { Consiste en evaluar la propia } \\
\text { comprensión, detenerse y volver a leer, } \\
\text { encontrar relaciones de ideas para la } \\
\text { creación de significados. }\end{array}$ & $\begin{array}{c}\text { LECTURA } \\
\text { INDEPENDIENTE O } \\
\text { INDIVIDUAL } \\
\text { (En voz baja o en silencio) }\end{array}$ \\
\hline
\end{tabular}




\begin{tabular}{|c|c|}
\hline \multirow[t]{2}{*}{$\begin{array}{l}\text { Tomado de imágenes educativas.com } \\
\text { https://www.imageneseducativas.com/tag/ } \\
\text { la- lectura-en-la-escuela/ }\end{array}$} & $\begin{array}{c}\text { LECTURA } \\
\text { COMENTADA } \\
\text { (Al terminar cada párrafo o al final de } \\
\text { la lectura, se comenta) }\end{array}$ \\
\hline & $\begin{array}{c}\text { LECTURA DE } \\
\text { EPISODIOS } \\
\text { (cuando la lectura es muy larga y se } \\
\text { deja la continuidad para otro } \\
\text { momento) }\end{array}$ \\
\hline
\end{tabular}

- Piensan que la familia y el entorno son elementos de suma importancia en el proceso de aprendizaje. En las propuestas toman en cuenta las actividades "para leer con papá o mamá", estableciendo una corriente de comunicación hogar-escuela, donde los primeros permanecen junto a los niños durante todo el proceso. Además, no olvida destacar que la familia y el entorno los estimulan mucho antes del ingreso al grado transición.

- La mayoría de las docentes adaptan el conocimiento que poseen acerca de las diferentes teorías a cada situación de aprendizaje, seleccionando de éstas los aspectos que consideran más relevantes; otras en cambio mencionan estar de acuerdo con una concepción de aprendizaje que aplican en su quehacer diario.

- Para la ejecución de la investigación se requerirán de varios recursos materiales como: libreta de apuntes, cuestionarios, formularios de encuestas.

- Se realizaron actividades de pre lectura, de lectura y post lectura.

\section{Con respecto a los estudiantes:}

- Todos los niños reflejaron buena comunicación con sus docentes. La misma permitió que éstos demostraran interés en las actividades de Lectura propuestas.

- La mayoría de los niños de cinco años leían sus propios nombres.

- La mayoría de los niños de seis años podían leer los textos que se le presentaran.

Solo 3 o 4 niños no alcanzaron sus logros por no asistir regularmente a la escuela por diversos motivos.

Los niños en este nivel solo están en la capacidad de aprender los cinco fonemas vocálicos y la combinación de ellas en diptongos, triptongos y siete fonemas consonánticos /m/, /p/, /s/, /l/, /n/, /f/ pero si alcanza este propósito antes de la culminación se les sigue enseñando progresivamente los demás fonemas. 
Se comprobó que el mejor maestro de niños es otro niño más aventajado.

Este último logro fue alcanzado por el $80 \%$ de los niños un poco por encima de la media del distrito $62 \%$ en este año.

Se discriminó su desarrollo así:

Excelentes, 28\% leían apropiadamente.

Sobresalientes, $52 \%$ aprendieron más de los 7 fonemas consonánticos entre hasta 16.

Aceptables, 20\% solo alcanzaron los fonemas vocálicos y entre 3 a 6 consonánticos

\section{Con respecto a la adecuación de las aulas de clase:}

- Los ambientes son amplios y adecuados al tamaño de los niños. Todo está al alcance de ellos. Esto favorece la labor educativa.

- Cada sala posee un rincón donde se encuentran diferentes materiales de lectura: libros de cuentos traídos por los niños, tarjetas con dibujos acompañadas de un texto, historietas, etc.

- En las salas hay también calendarios con los días de la semana, el mes del año que se actualizan día a día por los niños.

- Todas las salas cuentan con carteleras que muestran los diferentes trabajos de los niños

En las mismas se colocan carteles que explican el tema tratado.

\section{Reflexiones finales}

En el presente trabajo de investigación se realizó un rastreo bibliográfico o revisión de la literatura sobre el tema, a fin de obtener un referente teórico que nos permitiera establecer lo que en materia de lectura inicial ha surgido en los últimos años. Consecuentemente se inició el desarrollo del marco teórico con una breve reseña de las concepciones más reconocidas, a fin de precisar los avances producidos en este campo, objeto de nuestro estudio.

Se pudo establecer que las características del niño de hoy incentivan a los docentes a incorporar las actividades de lectura en sus aulas. Se observó que... 
1) los niños son los que promueven y exigen esas actividades y por eso el salón de clase se transforma en el mejor lugar para volcar sus inquietudes.

2) En ella se comparten sus intereses y aptitudes no sólo con su docente sino también con sus compañeros de clase, en un intercambio que produce una motivación que los lleva a buscar materiales y a investigar, para intentar leerlos para sí o para sus compañeros o padres.

3) Aunque durante el periodo escolar se interese al niño para la lectura, este solo incentivo no garantiza para que el niño continúe leyendo en grados posteriores

4) En el grado de transición la lectura llena mucho campo de intereses (aventuras), pero al variar estos se tiende a dejar de leer. Se requiere la motivación extrínseca.

5) Para algunos niños la lectura está asociada con las actividades escolares mientras que otros más de la mitad continúan leyendo en sus hogares fuera del periodo de clases, fines de semana, festivos y vacaciones.

6) Existen otros medios de entretenimiento y esparcimiento distinto a la lectura, por ello los padres deben colaborar de manera decidida. 


\section{Referencias bibliográficas}

Barnett, W. S. \& Ackerman, D. J., (2005). Prepared for Kindergarten: What Does" readiness" Mean?. Nieer.

Ballesteros Valencia, Harold (2013). La facultad predictiva del lenguaje. De la comunicación celular a la comunicación digital de Juan José Trillos Pacheco. Utopía y Praxis Latinoamericana, vol. 18, núm. 60, enero-marzo, 2013, pp. 131-132. Universidad del Zulia Maracaibo, Venezuela. Disponible en: http://www.redalyc.org/articulo.oa?id=27926711012 .

Bavister, S., \& Vickers, A. (2011). Programación neurolingüística (PNL): Las claves para una comunicación más efectiva. Editorial AMAT.

Bravo Valdivieso, L., Villalón, M., \& Orellana, E. (2004). Los procesos cognitivos y el aprendizaje de la lectura inicial: diferencias cognitivas entre buenos lectores y lectores deficientes. Estudios pedagógicos (Valdivia), (30), 7-19.

Bravo Valdivieso, L., Villalón, M., \& Orellana, E. (2006). Diferencias en la predictividad de la lectura entre primer año y cuarto año básicos. Psykhe (Santiago), 15(1), 3-11.

Bustillos, J. K. L., \& Reyes, V. (2018). Actitudes de los niños hacia las Ciencias Naturales. Una aproximación interpretativa desde el escenario de la Educación Inicial. Revista de Ciencias de la Educación, Docencia, Investigación y Tecnologías de la Información., CEDOTIC 3(2), 21-21.

Mendoza, Q., \& Verónica, B. (2015). Habilidades metacognitivas de la docente parvularia (o) y su influencia en la creatividad en los niños de 5 a 6 años (Bachelor's thesis, Universidad de Guayaquil Facultad de Filosofía, Letras y Ciencias de la Educación).

Penfield, W., \& Perot, P. (1963). The brain's record of auditory and visual experience: a final summary and discussion. Brain, 86(4), 595-696.

Soto, J. (2017). Desde una ontología del lenguaje hacia una ética intercultural de la alteridad. Amauta, 15(30), 135-150.

Soto, J. (2016). Fundamentos epistemológicos y cognitivos de las investigaciones sociales y humanas. Revista de Ciencias de la Educación, Docencia, Investigación y Tecnologías de la Información CEDOTIC., 1(1).

Stanovich, K. E., Nathan, R. G., \& Vala-Rossi, M. (1986). Developmental changes in the cognitive correlates of reading ability and the developmental lag hypothesis. Reading research quarterly, 267-283. 
Sulzby, E., Teale, W. H., \& Kamberelis, G. (1989). Emergent writing in the classroom: Home and school connections. Emerging literacy: Young children learn to read and write, 63-

Tabors, P. O. \& Dickinson, D. K. (2001). Beginning literacy with language: Young children learning at home and school. Paul H Brookes Publishing.

Trillos Pacheco, J. J. (2011). La facultad predictiva del lenguaje: De la comunicación celular a la comunicación digital. Editorial Uniautónoma del Caribe. Barranquilla, Colombia.

Valdivieso, L. B. (2013). Lectura inicial y psicología cognitiva. Ediciones UC.

Venegas, P. F. M., \& Roa, J. D. D. V. (2019). La motivación hacia la lectura de textos literarios. Revista de Ciencias de la Educación, Docencia, Investigación y Tecnologías de la Información CEDOTIC., 4(1), 95-114.

Wadsworth, B. J. (1996). Piaget's theory of cognitive and affective development: Foundations of constructivism. Longman Publishing.

https://www.imageneseducativas.com/tag/la-lectura-en-la-escuela/ consultado el 26 de noviembre de 2019. 
